If $30 x-7=0$. 


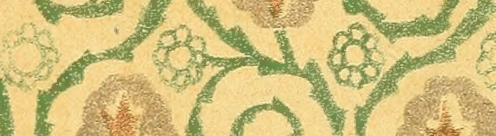

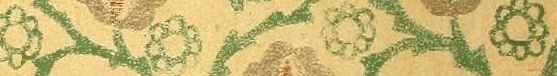
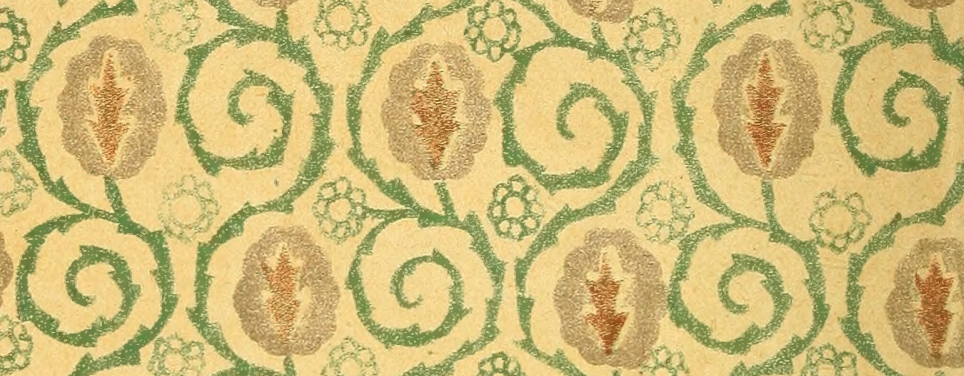

89.

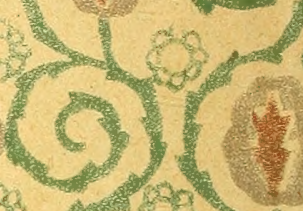

80

管

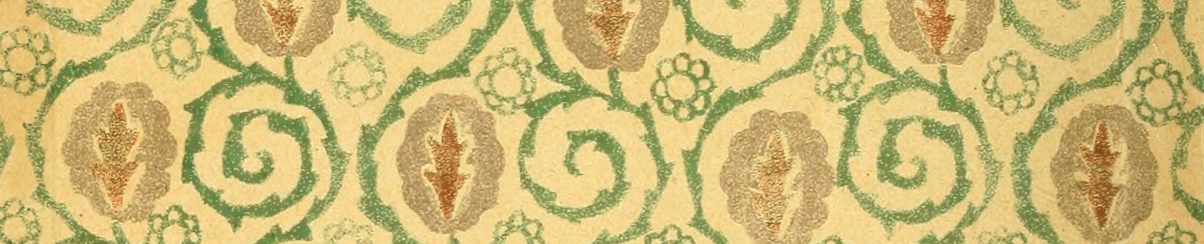

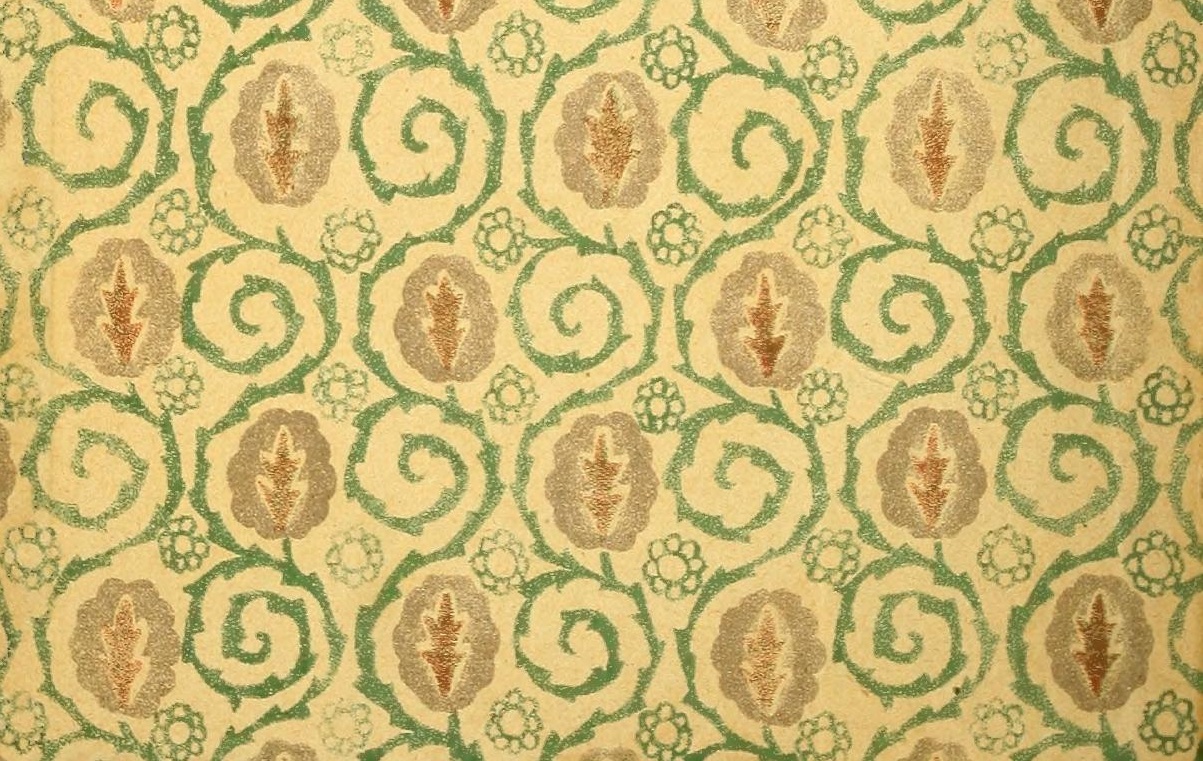






\section{Analecta hemipterologica}

auctore

Carolo stål.

\section{(1) e laspin $S$ tå.}

Hem. afr. I. p. 2.

Typus generis: Plataspis ruficeps Dall.

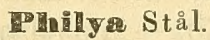

Hem. afr. I. p. 33.

Ad hoc genus pertinent Callidea Senator Fabr., Jactator Stål (= gloriosa Voll.), ditissima Voll., fastuosa Voll. et elegans Montr., nec non Scutellera metallica Montr., et leucocyanea Montr.

\section{Calliphara Germ.}

Stal Hem. afr. I. p. 34.

a. Angulis apicalibus segmentorum abdominis secundi, tertii, quarti et quinti spina armatis; rostro medium segmenti secundi ventris subattingente; articulo primo antennarum secundo fere triplo longiore; ventre impunctato.

1. C. Peronii Guér. Flavo-testacea, nitida, supra punctulata; antennis rostroque nigris; capite, macula anteriore, marginibus imis lateralibus anticis vittaque thoracis intra margines illos posita et ante medium cum iisdem confluente, parte exteriore hemelytrorum, pectore maculague oblonga laterali marginali segmentorum tertii, quarti, quinti et sexti veniris coeruleis; segmento ultimo ventris segmentoque anali nigris, hoc basi aeneo; margine costali corii ante medium flavo-testaceo; membrana fusca. $\delta$. Long. 18, Lat. 9 Mill. - Timor. (Coll. Guérin et Stål.)

Scutellera regalis var. Peronii Guér. Voy. de la Coq. p. 155 Atlas pl. 11. fig. 4. (1838) sec. ex. typ.

Callidea regia Voll. Ess. Faun, entom. Arch. Ind. Neerl. Fam.

Scutel. p. 16. 1. (1863). 
Figura Guerini male colorata, descriptio incorrecta.

aa. Segmento secundo ventris in angulis apicalibus spinula destituto.

b. Angulis apicalibus segmentorum abdominis tertii, quarti, quinti et interdum sexti spinula vel denticulo armatis.

c. Ventre impunctato, obsolete aciculato vel punctis rarissimis consperso.

2. C. imperialis Fabr. - Callidea imperialis Dall. List of Hem. I. p. 24. 9. (1851). - Nova Hollandia. (Mus. Holm. et Coll. Stål.)

3. C. Billardierii Fabr. - Callidea Billardieri Voll. Ess. Faun. entom. Arch. Ind. Neerl. Fam. Scutell. p. 16. 2. (1863) = Scutellera splendida Montr. Ann. des Scienc. phys. et nat. Ser. 2. VII. 1. p. 94. (1855). - Amboina, Woodlark. (Coll. Stål.)

4. C. Caesar Voll. - Callidea Caesar Voll. Ess. Faun. ent. Arch. Ind. Neerl. Fam. Scutell. p. 21. 9. Pl. 2. fig. 1. (1863). - Insula Buru. (Mus. Holm.)

Rostrum segmentum tertium ventris attingit.

5. C. Praslinia Guér. Viridi-aenea, subcoeruleo-nitida; antennis, rostro, macula antica thoracis, maculis septem scutelli, pedibus ventreque nigris, hujus limbo margineque apicali segmentorum viridi-aeneis; thorace ante medium parce subtiliterque, scutello densius, disco subtilius, latera versus distinctius punctulatis; articulo primo antennarum secundo fere plus duplo longiore; rostro basin segmenti secundi ventris attingente vel subsuperante. ‥ Long. 19, Lat. 9 Millm. - Port Praslin Novae Irlandiae. (Coll. Guérin.)

Scutellera Praslinia Guér. Voy. de la Coq. p. 158 et 160. Atlas Pl. 11. fig. 3. (1838) sec. ex. typ.

Pars dimidia basalis tibiarum anticarum et partes duae tertiae tibiarum posteriorum superne convexae, nec sulcatae.

Maxime incorrecte haec species a D. Dallas cum C. excellenti conjungitur.

Exemplum ex insulis, quae Novae Hebrides dicuntur, reportatum, in Museo Regio Holmiensi asservatum, totum subcoeruleo-nigrum, thorace toto dense punctato instructum, ad C. Prasliniam refero. 
cc. Ventre latera versus dense distineteque punctato.

6. C. excellens Burm. - Callidea praslinea Dall. List of Hem. I. p. 24. 10. (1851) excl. syn. Guérinii. - Manilla. (Mus. Holm. et Coll. Stål.)

Articulus secundus antennarum elongatus, primo nonnihil brevior.

bb. Angulis apicalibus segmentorum abdominis inermibus vel segmento quintovel segmentis quarti et quinti denticulo minutissimo et obsoleto instructis; capite parviusculo.

d. Ventre latera versus, thorace scutelloque dense punctatis.

7. C. Buquetii Guér. - Scutellera Buquetii Guér. Voy. de la Coq. p. 159 et 162 (1838) sec. ex. typ. - Java, Timor, Hongkong. (Coll. Stål.)

Obs. Cimex nobilis, qui a D. Dallas ad hane speciem refertur, in dissertatione "Centuria Insectorum rariorum" a Linné hoc modo describitur:

"Cimex nobilis scutatus viridi auratus nigromaculatus.

Habitat in Java.

Magnitudo Apis Bombylii; ovatus. Caput viridi-aeneum. Thorax viridi-aeneus, maculis 7 fusco-coerulescentibus. Scutellum viridi-aeneum, tegens totum dorsum maculis trium parium coeruleis. Corpus subtus rufo-aeneum. Abdominis segmenta singula subtus utrinque maculis duabus coeruleis. Antennae fuscae, corpore breviores. Femora omnia sanguinea. Tibiae coeruleae. Alae fuscescentes: superiores costa marginali viridi-aenea. ${ }^{6}$

dd. Lateribus ventris, thorace scutelloque parce punctatis.

8. C. eximia Voll. - Callidea eximia Voll. Ess. Faun. ent. Arch. Ind. Neerl. Fam. Scutell. p. 20. 8. Pl. 1. Fig. 8. (1863). - Ternate. (Coll. Stål.)

Specimen collectionis meae fere totum obscure coeruleum, supra nigro - maculatum, ventre nigro, disco in flavo - testaceum vergente, lateribus apiceque segmentorum coeruleis insigne, ad $\boldsymbol{C}$. e xi miam refero; e Novis Hebridibus est reportatum.

9. C. munda Stål. Viridi-aenea, nitida; antennis rostroque nigris, hoc basin segmenti tertii ventris attingente; callis anticis maculisque quattuor thoracis, in seriem transversam mediam dispositis, maculis septem scutelli, una inter has subapicali, impressione 
laterali segmentorum ventris, apice femorum, tibiis tarsisque nigrocoeruleis; scutello ventreque aureo - nitidis, hujus disco parvo, angusto, obsoleto, femoribusque flavo-testaceis; margine abdominis inermi. $\sigma$. Long. 12, Lat. 6 mill. - China. (Coll. Stål.)

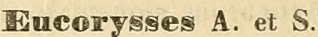

Stål Hem. afr. I. p. 34.

a. Capite nigro, lateribus partis anteocularis flavescentibus vel flavo-testaceis, interdumviolaceo-nitidis.

1. E. grandis Thunb. - Rostro medium segmenti tertii ventris subattingente.

var. a. Niger; thorace, scutello, maculis pectoris ad coxas, maculaque transversa media segmentorum quarti et quinti ventris flavo-testaceis; marginibus thoracis scutellique violaceo-nitidis; margine omni angusto, macula discoidali angulisque lateralibus thoracis, limbo basali, macula prope basin, macula utrinque laterali transversa ante medium posita, fascia abbreviata pone medium maculaque obsoleta subapicali scutelli nigris; macula angulorum basalium segmentorum ventris flavo-testacea, valde violaceo-induta. 오.

Cimex grandis Thunb. Nov. ins. spec. II. p. 31. Tab. 2. Fig. 46. (1783) sec. ex. typ.

Callidea grandis Dall. List of Hem. I. p. 23. 4. (1851).

var. $b$. Flavescens vel flavo-testaceus; antennis, rostro, macula antica thoracis, limbo basali maculisque tribus ante medium scutelli, pectore, fascia laterali postica segmentorum, plaga basali maculaque apicali ventris nec non pedibus nigris; maculis pectoris sex, tribus ad coxas, tribus ad margines laterales, flavescentibus.

Cimex Baro Fabr. Ent. syst. Suppl. p. 528. 7 -8. (1798.)

Callidea Baro Dall. List of Hem. I. p. 22. 3. (1851.)

aa. Capitis parte anteoculari toto concolore.

b. Rostro apicem segmenti quartiventris attingente.

2. E. sexmaculatus Leach = Scutellera sexmaculata Leach Zool. mise. II. p. 36. Tab. 14. (1815) = Scutellera arrogans Montr. Ann. Soc. Linn. Lyon. Nouv. Sér. V. p. 258 (1858). - Insula Lifu. (Coll. Stål); Nova Caledonia (sec. Leach).

bb. Rostro basin segmenti tertii ventris attingente vel subsuperante.

3. E. atricapillus Guér. Capite violaceo aeneo; ventro rufo. testaceo, plus minus nigro-variegato; antennis, rostro pedibusque nigris. 
var. $a$. Thorace, scutello limboque laterali prostethii rufo-testaceis; macula interdum deficiente thoracis, maculis fasciisve abbreviatis scutelli nigris. $\sigma^{\circ}$ \&. - Java. (Coll. Stål.)

Callidea atricapilla Dall. List of Hem. p. 24. 7. (1851.)

var. $b$. Thorace, scutello pectoreque aeneis, plus minus purpurascentibus, nigro-maculatis et fasciatis. $\sigma^{\top}$ ㅇ. - Insula Bali. (Coll. Stål.)

Callidea variabilis Voll. Ess. Faun. ent. Arch. Ind. Neerl. Fam. Scutell. p. 22. 10. Pl. 1. fig. 9. (1863) sec. ex. typ.

\section{Thamprophara Stal.}

Hem. afr. I. p. 34

Typus generis: Callidea bifasciata White.

\section{Cosmocoris Stål.}

Hem. afr. I. p. 34.

Ad hoc genus pertinent Callidea sellata White, chromatica White, excavata Guér. (= gibbosa Voll.), quadrimaculata Voll. et Schlegelii Voll.

\section{Lamprocoria $S \mathrm{t}$ a $\mathrm{l}$.}

Hem. afr. I. p. 34.

Ad hoc genus pertinet Callidea lateralis Guér.

Graptophara $S$ tål.

Hem. afr. I. p. 34.

Typus generis: Callidea Reynaudii Guér.

Crraptocoroi Stål.

Ad hoc genus etiam referenda est Callidea Stålii Voll.

Timmicorion Hahn。

1. E. Peregrinat or lin. Late ovatus, stramineus; antennis, annulo subapicali femorum, annulo subbasali apiceque tibiarum nec non fasciis limbi abdominis, apicem et basin segmentorum occupantibus, nigris; thorace parteque basali elevata scutelli ferrugineo-nigris, minute remoteque stramineo-conspersis; callo angulorum basalium scutelli laevi, siramineo; parte vix dimidia apicali scutelli, basi fasciaque lacerata pone medium hemelytrorum lateribusque pectoris fusco-ferrugineis, his pallido-variis; fasciis marginalibus nigris ventris intus confluentibus; articulo antennarum primo basi, apice et superne, nec non annulo prope basin articuli secundi stramineis. 8 . Long. 14, Lat. thor. 8 mill.

Cimex peregrinator Lin. Mus. Lud. Ulr. p. 173. 7. (1764) sec. ex. typ. Linné $i$ in Mus. Upsaliensi. 
E. varioloso valde affinis, colore antennarum parteque straminea scutelli et hemelytrorum laevi, impunctata, praesertim diversus. Thorax et pars basalis scutelli fortiter rugoso-punctati. Pars apicalis scutelli, basis et fascia posterior hemelytrorum distincte et dense punctulatae. Articuli duo basales antennarun soli restant in exemplo typico.

Exemplum Musei Holmiensis e Brasilia boreali ad hanc speciem forte est referendum; differt a typo pictura nigerrima, articulo antennarum primo toto nigro, parte pallida scutelli et hemelytrorum remote nigro-punctatis.

Prochymena A, et $\mathrm{S}$.

1. B. Poeyi Guér. A Brochymena haedula Stål, cui quoad staluram et formam thoracis est simillima, differt capite longiore, lobis lateralibus lobo medio nonnihil longioribus, antice convergentibus et subcontiguis, apice hiscentibus, tibiis anticis gracilioribus, angulis earum pone medium haud subdilatatis, coloregue pallidiore.

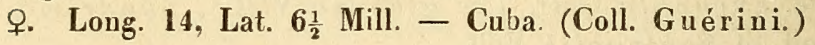

\section{Cuspicona $\mathrm{D}$ all.}

1. C. viridis Montr. C. prasinatae Stål simillima, punctura remotiore, lamina sternali coxas anticas haud vel vix superante, nec fere ad apicem prostethii producta, distinctissima. Long. $8 \frac{1}{2}$, Lat. 5 Mill. - Woodlark, Lifu, Nova Caledonia. (Coll. Signoret et $S$ tål.)

Pentatoma viride Montr. Ann. Scienc. phys. et natur. Sér. 2. VII. p. 98. (1855.)

Cuspicona viridis 11 ontr. et Sign. Ann. ent. Sér. 4. I. p. 65. 20. (1861) sec. ex. typ.

\section{Tanasa Stål.}

1. B. glauca Fabr. Pallidissime olivaceo-straminea, supra sat dense punctata; thorace ante medium capiteque laeviusculis, hoc obsolete ruguloso; prostethio, metastethio postice ventreque punctulatis; tibiis cylindricis, haud sulcatis; membrana alisque vitreis, illa basi prope angulum apicalem clavi macula minutissima nigra notata; antennarum articulo secundo tertio paullo breviore; articulo secundo rostri tertio paullo longiore; mesosterno distincte carinato; metasterno haud elevato (?); ventre basi leviter tuberculato. ㅇ. Long. 11 $\frac{1}{2}$, Lat. 7 Mill. - Insula Lifu. (Coll. Signoret.)

Cimex glaucus F abr. Ent. syst. IV. p. 118. 149. (1794.)

Edessa glauca Fabr. Syst. Rhyng. p. 154. 41. (1803.)

Pentatoma punctum Montr. et Sign. Ann, ent. Sér. 4. I. p. 64.

14. (1861) sec. ex. typ.

Statura fere Piezodori flavuli. 
Sangariug Stål.

Hem. afr. I. p. 219.

1. S. paradoxus Stål. Dilute ferruginea-stramineus, supra vemote ferrugineo-punclatus, subtus cum pedibus pallidior et dilute punctatus; antennis dilute ferrugineis, articulo apicali apice fuscescente: angulis imis basalibus sculelli, macula minuta pone medium angulogue imo apicali corii nigricantibus; membrana livida, dilute fusco-venosa. $\sigma^{\top}$ S. Long. $11 \frac{1}{2}-14$, Lat. 5-6 mill. - Australia occidentalis. (Mus. Holm.)

Caput ovatum, planum, nonnihil longius quam cum oculis latius, marginibus lateralibus leviter sinuatis. Thorax duplo et dimidio latior quam longior, antrorsum sat angustatus, ante medium planus, marginibus lateralibus rectis, leviter reflexis. Hemelytra basi paullo dilatata, dein retrorsum sat angustata et abdomine multo angustiora. Segmentum anale maris retusum, utrimque processu sat longo, subtriquetro, retrorsum et extrorsum vergente, et praeterea spinulis tribus armatum.

\section{Panaetỉ Stål.}

Hem. afr. I. p. 220.

1. P. lobulatus Stål. Stramineo-albidus, supra cum pectore distincte fusco-ferrugineo-punctatus; maculis parvis duabus mediis thoracis, anteriore minutissima, obsoleta, altera subtransversa, calloque angulorum basalium scutelli stramineis, laevibus; scutelli maculis duabus basalibus parteque apicali minus dense punctatis; membrana fuscescente; vilta laterali lata ventris, interdum abbreviata, nigra vel fusco-testacea; pedibus interdum fusco-annulatis. $\sigma$ ㅇ. Long. 5 , Lat. 3 mill. - Australia borealis. (Mus. Holm.)

Caput apice rotundato - truncatum, lateribus ante oculos parallelis. Thorax anterius valde declivis, angulis anticis in lobum pallidum, oblique antrorsum vergentem, productis, angulis lateralibus in spinam depressam, latam, apice sinuato-truncatam, extrorsum productis. Scutellum apice rotundatum, frenis vix ad medium extensis. Anguli apicales segmentorum abdominis acute prominuli.

\section{Plisthenes $\mathrm{S}$ tål.}

Hem. afr. I. p. 224.

Ad hoc genus pertinet Tessaratoma dilatata Montr.

Axoma Stål.

Hem. afr. I. p. 224.

Ad hoc genus pertinet Rhaphigaster longitudinalis Westw. in Hope Cat. of Hem. I. p. 31. (1837.) 


\section{Virbius Stål.}

Hem. afr. I. p. 226 .

Ad hoc genus pertinent Pycanum imperiale Dohrn et angulatum Stål.

\section{Petillia Stål.}

Hem. afr. II. p. 2.

Trematocoris II ayr Verh. zool. bot. Ges. Wien 1865. p. 431.

Ad hoc genus pertinent Mictis tragus $\mathrm{Fabr}$., lobipes Hope, dentipes A. et S., calcar Dall., grossa Dall. et valida Dall.

\section{Helonug Stål \\ Hem. afr. II. p. 3.}

Ad hoc genus pertinet Amorbus discolor Dall.

Myrsilus S tål.

Hem. afr. II. p. 3.

Ad hoc genus pertinent Nemalopus flaviceps Guér. et albithorax Boisd.

\section{Pachylis Lep. et Serv.}

1. P. laticornis Fabr., Dall. In dissertatione "Insectorum hemelytrorum tria genera illustrata ${ }^{66}$ haec species a Thunberg sub his nominibus describitur:

Pendulinus striatus Thunb. 1. c. p. 6. 6.

- bipunctatus Thunb. 1. c. p. 6. 7.

- bidentatus Thunb. 1. c. p. 7. 8.

- gigas Thunb. 1. c. p. 7.9.

- grossus Thunb. 1. c. p. 7. 10.

Exempla typica $\boldsymbol{P}$. gigantis et grossi examinavi; $\boldsymbol{P}$. striatus, bipunclatus et bidentatus secundum figuras Stollii 181, 182 et 231 sunt descripti.

\section{Acanthocoris A. et S.}

1. A. scaber Lin. - Cimex scaber Lin. Centur. ins. rar. p. 17. 43. $(1763)=$ Cimex sordidus Thunb. Nov. ins. spec. II. p. 44. $(1783)=$ Alydus scaber Thunb. Hem. rost. cap. III. p. 2. $(\mathbf{1 8 2 2})=$ Acanthocoris scabrator Fabr. Dall.

Exempla typica Thunbergii examinavi. Tibiae anticae sublineares. Articuli antennarum primus et secundus, qui in exemplis typicis soli restant, apud $\boldsymbol{A}$. sordidum breviores quam apud $\boldsymbol{A}$. $\boldsymbol{s c a}$ brum; anguli laterales thoracis apud $A$. scabrum acutiores et magis prominuli quam apud $\boldsymbol{A}$. sordidum.

Petalops A. et S.

1. P. thoracicus Thunb. $=$ Cimex thoracicus Thunb. 
Nov. ins. spec. II. p. 39. (1783) = Petalops elatus Fabr., Dall. List of Hem. II. p. 433. 1. (1852) sec. ex. typ. Thunbergii.

\section{Plapigigus Stål.}

1. P. spinosus Thunb. Cinnamomeus, subtus flavescente-cinnamomeus; antennis dorsoque abdominis nigris, illarum arliculo tertio foliaceo, ovato, nonnihil longiore quam latiore, basi ipsa albida; fascia abbreviata prope basin maculaque transversa reclangulari prope apicem donsi abdoninis stramineis; membrana fusca; alis vitreis, fusco-venosis; fascia angusta basali abbreviala fasciolaque obliqua laterali segmentorum ventris nigricantibus; femoribus apicem versus tibiisque infuscatis, harum annulo pallido. ${ }^{7}$. Lons. 10, Lat. 3 mill. - Cayenna. (Coll. Thunberg.)

Pendulinus spinosus Thunb. Ins. hem. tria gen. ill. pag. 8. 12. (1825) sec. ex. typ.

Caput pone oculos callosum, iuberculis antenniferis apice inlus acute productis. Thorax angulis anticis pone collare spinula armatis, angulis lateralibus in spinam, extrorsum vergentem, gracilem, productis, angulis posticis vix prominulis. Femora intermedia subtus in latere posteriore spinulis duabus armata.

Pedes exempli descripti antici et postici mutilati.

\section{Chariesterm Lap.}

1. C. armatus Thunb. Cinnamomeus, griseo-sericeus, subtus cum pedibus pallidior; abdomine dor'so subsanguineo, basi apiceque nigro; alis vilreis, fusco-venosis; femoribus anterioribus subtus prope apicem spinulis duabus, posticis spinulis tribus armatis; tibiis in-

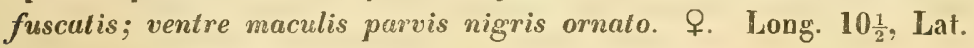
3 mill. - (Coll. Thunberg.)

Pendulinus armatus Thunb. Ins. hem. tria gen. ill. pag. 8. 13. (1625) sec. ex. typ.

Chariesterus gracilis Lap. Ess. Hém. p. 44. Pl. 53. Fig. 6. (1832.)

Caput antennaeque exempli typici mutilata. Thorax collari destitutus, marginibus lateralibus convexis, inermibus, angulis lateralibus spina nigra armatis, marginibus lateralibus posticis anterius denticulis duobus minutissimis instructis, angulis posticis retrorsum nonnihil prominentibus.

\section{耳yrnessus Stål.}

1. L. tibialis Stål = Leptocorisa geniculata Guér. Exemplum typicum Cubanum Guérinii exemplis Brasiliensibus nonnihil minus, praeterea simillimum. 


\section{Tliponius Stål.}

Hem. afr. II. p. 5.

1. T. unipunctatus Thunb. Stramineus, supra cum connexivo ferrugineo-fusco-punctulatus; antennis graciliusculis, articulis secundo et tertio in rufescentem vergentibus; marginibus lateralibus thoracis pallidis; maculis minutis una pone medium corii, una laterali mesostethii et metastethii compluribusque ventris nigris; alis infuscatis; articulo quarto rostri tertio paullo longiore. Q. Long. 15, Lat. thor. $4 \frac{1}{2}$, Lat. abd. 7 mill. - Japonia. (Coll. Thunberg.)

Cimex unipunctatus Thunb. Nov. ins. spec. II. p. 38. Tab. 38.

fig. 52. (1783) sec. ex. typ.

Tliponius marginellus (= Gonocerus marginellus Herr.-Sch. Wang. Ins. fig. 562) differt a $T$. unipunctato statura minore, angulis lateralibus thoracis nonnihil acutioribus, abdomine connexivoque paullo angustioribus, hoc haud fusco-punctato.

\section{Cneius Stål.}

Hem. afr. II. p. 4.

1. C. dentipes Stål. Nonnihil elongatus, pallidissime griseo vel tesiaceo-flavescens, supra ferrugineo vel fusco-ferruginen-punctatus; antennis obscurioribus, articulis primo, secundo et tertio apicem versus fuscis, ultimo basi pallido; thorace marginibus lateralibus stramineis, anterius intra margines illos lineola nigro-fusca notato; hemelytris femoribusque interdum fusco-conspersis, margine costali basin versus nigricante; membrana fusca; alis leviter infuscalis; abdomine dorso dilute croceo; vittis duabus geminis interdum deficientibus mesosterni punctoque angulorum apicalium segmentorum ventris nigris. $\delta$ ㅇ․ Long. 11, Lat. 3 mill. - Australia borealis. (Mus. Holm.)

Antennae teretiusculae, crassiusculae, corpore paullo breviores, articulis primo et secundo aeque longis, duobus ultimis illis paullo brevioribus, penultimo ultimo paullo longiore. Thorax marginibus lateralibus rectis, angulis lateralibus haud prominulis.

Mutusea Stål.

Hem. afr. II. p. 6.

Ad hoc genus pertinent Leptocorisa brevicornis $\mathrm{D}$ all. et prolixus Stål.

Pactye Stål.

Hem. afr. II. p. 152.

1. P. Ciconia Stål. Nigricans, parce fusco-pilosa; hemely- 
tris, abdomine femoribusque obscure fusco-testaceis; limbo basali thoracis, margine costali maculaque marginali ante medium corii nec non macula ante medium membranae sordide albidis; fascia angusta arcuata capitis pone ocellos, articulis secundo, tertio et quarto antennarum, coxis, basi femorum posteriorum, tibiis tarsisque pallide testaceo-stramineis; articulis antennarum secundo et tertio apice nec non dimidio apicali articuli ultimi nigro-fuscis; thorace posterius hemelylrisgue punctulatis. ㅇ․ Long. 8, Lat. 2 mill. - Sarawak, Borneo. (Mus. Holm.)

\section{Narbo Stål.}

Hem. afr. II. p. 153.

1. N. longipes Stål. Niger; lineola longitudinali antica lobi postici thoracis, apice scutelli, maculis nonnullis minutis ante medium membrenae, maculis duabus oblongis mediis marginum lateralium ventris, trochanteribus, basi femorum nec non annulo parvo subbasali articuli quarti antennarum dilute testaceo-flavescentibus; corii margine costali ante medium, lineola media marginis apicalis lineolaque prope apicem marginis cosialis et marginem ipsum occupante testaceo-albidis. $\sigma^{\top}$. Long. 11, Lat. 2 mill. - Sarawak. (Mus. Holm.)

Antennae corpore fere longiores, articulis secundo et tertio aeque longis, primo paullo longioribus. Thorax lobo postico distincte punctulato. Hemelytra punctulata, punctis in series dispositis; lineolis duabus longitudinalibus prope apicem membranae sordide albidis.

\section{Wuander $S$ tål.}

Hem. afr. II. p. 154.

Ad hoc genus pertinent Rhyparochromus lacertosus Er. et pictipennis Dall.

Plociomera Say.

1. P. (Pamera) nodosa Say $=$ Aphanus clavatus Dall.

Gyndes Stål.

Ad hoc genus etiam referendus est Rhyparochromus cephalotes Dall.

\section{Cnemodus H. -Sch.}

1. C. brevipennis Herr.:Sch. = Astemma mavortia Say New Harm. Ind. Dec. 1831; Compl. writ. Ed. Leconte I. p. 337. (1859).

\section{Lygaeus Fabr.}

1. L. sordidus Dall. Novam Hollandiam inhabitat. 
2. L. maculicollis Germ. = L. rubricosus Stål.

3. L. mactans Stål. Coccineus; capitis lobo medio apice maculaque basali utrimque ad oculos, antennis, rostro, thorace, scutello, apice clavi, macula vel fascia media corii, membrana, peciore, macula angulorum basalium segmentorum segmentisque duobus ultimis ventris, ano pedibusque nigris; articulo primo antennarum interdum, lateribus thoracis pone medium, angulis posticis prostethii lateribusque segmenti quinti ventris coccineis; macula discoidali, angulo basali, margine basali limboque membranae albidis. ㅇ. LLong. 9 $\frac{1}{2}$, Lat. 3 mill. - Australia borealis, Sidney, Insulae Fidschi. (Mus. Holm.)

4. L. luctuosus Stål. Niger, nigro-pilosus; capite, thorace ante medium, pectore segmentoque primo ventris flavescentibus; thoracis margine postico utrinque inter scutellum et angulos laterales nonnihil dilatata, ejusdem carina longitudinali ante medium, nec non macula laterali mesostethii et metastethii nigris. ㅇ. Long. 12 , Lat. 4 mill. - Brasilia borealis. (Mus. Holm.)

5. L. decoratus Stål. Coccineus; capitis lobo medio maculaque basali ad oculos, bucculis, antennis, rostro, thoracis fascia apicali, margines laterales haud allingente, lineolis duabus impressis oblique transversis anterioribus, villis duabus laliusculis, a basi ultra medium extensis, antice extus ad margines laterales obligue productis, nec non limbo postico, scutello, clavi margine apicali limboque ad suturam clavi, corii vilta obliqua media percurrente, limbo costali, excepta parte basali, margine apicali maculaque media vittam et limbum conjungente, membrana, pectore, macula angulorum basalium segmenti secundi, fascia basali segmentorum tertii, guarti et quinti segmentoque ultimo ventris nec non pedibus nigris: limbo lato antico limboque laterali prostethi, macula laterali segmentorum pectoris omnium maculaque laterali segmenti sexti ventris coccineis. ․ Long. 12, Lat. 4 mill. - Australia borealis. (Mus. Holm.)

6. L. pedestris Stål. Oblongo-ovalus, niger, griseosericeus et parce fusco-pilosus; macula basali parva capilis. thorace, macula scutelli, hemelytris rudimentariis, maculisque marginalibus abdominis testaceis; bucculis, limbo postico segmentorum omninm pectoris, limbo antico prostethi, acelabulisque flavo-albidis; limbo postico segmentorum pectoris macula parva nigra notatis; thorace vitt is diba-

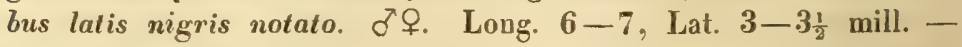
Sicilia, Tunis. (Mus. Holm.)

Species aptera, scutello hemelytrisque abbreviatis, aeque longis.

7. L. circumseptus Stål. Niger; bucculis, thoracis margine 
omni lineaque longitudinali percurrente, per scutellum continuata, clavi margine commissurali, marginibus apicali et costali corii, margine omni prostethii, margine postico mesostethii et metastethii, acetabulisque stramineis; margine suturali clavi, parte interiore corii ante medium ventregue sanguineis, hujus limbo, segmento ultimo anoque nigris, segmento ultimo stramineo-limbato. $\delta$. Long. 7, Lat. $2 \frac{2}{3}$ mill. - Tovar Columbiae. (Mus. Holm.)

L. xanthostauro valde affinis.

8. L. cardinalis Stål. Dilute sanguineus, remote fusco-pilosus; capitis lobo medio, antennis, rostro, thoracis limbo antico maculisque duabus posterioribus subtriangularibus, scutello, excepto apice imo, membrana, pectore, excepto limbo laterali prostethii, nec non segmentis apicalibus ventris, limbo laterali excepto, nigris; angulo basali, margine basali limboque angusto membranae albidis; capile anterius valde declivi. $\delta$. Long. $6 \frac{1}{2}$, Lat. 2 mill. - Australia borealis. (Mus. Holm.)

\section{retralaceus Fieb.}

1. T. rusticus Stål. Coccineus; capite, antennis, rostro, thorace, excepto limbo lato antico, scutello, parte costali corii, apice excepto, membrana, macula laterali segmentorum duorum apicalium ventris pedibusque nigris; tharace distincte, hemelytris obsolete pun-

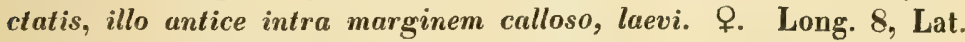
$2 \frac{1}{3}$ mill. - Australia borealis. (Mus. Holm.)

2. T. marginatus Thunb. Sanguineus, griseo-sericeus; antennis, rostro, macula obsoleta basali capitis, disco thoracis, scutello, apice excepto, clavo, interdum etiam corio, excepto margine costali, pectore, ventre pedibusque nigris; margine laterali pectoris, limbo laterali, interdum etiam medio segmentorum ventris sanguineis; membrana violaceo-fusca, apice albido-limbata. ㅇ. Long. 14, Lat. $3 \frac{1}{3}$ mill. - China. (Mus. Holm.) Terra capensis. (sec. Thunberg.)

Alydus marginatus Thunb. Hem. rostr. cap. III. p. 3. (1822.)

Serinetha Sinae Stål Öfv. Vet. Ak. Förh. 1855. p. 185. 1.

Astacops Boisd.

1. A. nigripes Stål. Dilute sanguineus, laeviusculus; pectore, ventre connexivoque stramineis; antennarum articulis tribus ultimis apiceque articuli primi, dorso abdominis, fasciis abbreviatis pectoris ventrisque, nec non pedibus nigris; membrana alisque fuscis; articulo secundo antennarum tertio nonnihil longiore. ㅇ. Long. 11, Lat. 3 mill. - Manilla. (Coll. Stål.) 
2. A. villicus Stål. Niger, laeviusculus, pilosulus; antennis, capite, rostri articulis duobus basalibus, thoracis parte tertia antica, parte coriacea hemelytrorum, prostethio ante medium pedibusque testaceis vel subsanguineis; parte apicali corii nigra; membrance fusca, pone medium decolore; vitta laterali intramarginali apiceque ventris flavo-albidis; antennarum articulo ultimo fusco, arliculis secundo et tertio aeque longis. ㅇ․ Long. 9, Lat. $2 \frac{2}{3}$ mill. - Nova Guinea. (Coll. Stål.)

3. A. nugax Slål. Testaceo-flavescens, in subsanguineum vergens; abdomine sordide flavo-albido; antennarum articulis duobus ultimis apiceque articuli secundi fuscis; articulo apicali rostri, scutello, basi hemelytrorum, mesostethio el metastethio fasciisque abbreviatis tribus pone medium ventris nigris; membrana fusca, pone medium pallidiore; articulo secundo antennarum tertio nonnihil longiore. ㅇ. Long. 11, Lat. 4 mill. - Nova Guinea. (Coll. Stal.)

\section{Arictus $\mathrm{S}$ tål.}

Hem. afr. III. p. 31.

Typus generis: Aradus Thoracoceras Montr.

Cinyphus S tål.

Hem. afr. III. p. 31.

Typus generis: Dysodius emarginalus Stål.

\section{Veleda $S t a ̊ l$.}

Hem. afr. III. p. 47.

1- V. Raptrix Stål. Fuscescente-testacea; membrana alisque infuseatis, fusco-venosis; lobo antico thoracis pectoreque griseo-flavescente-sericeis; maculis obligue transversis lateralibus ventris, in seriem dispositis, densissime flavo-albido-mucoreis. ․ Long. 11, Lat. 2 mill. - Australia borealis. (Mus. Holm et Coll. A. Dohrn.)

Caput thoraci longitudine subaequale, parte postoculari parte anteoculari plus duplo longiore, apice spinis tribus, lateralibus longissimis, inter oculos et paullo pone eosdem spinis duabus armatum. Thorax lobo antico spinis parvis nonnullis et quattuor magnis, anticis posticis dimidio brevioribus, lobo postico posterius spinis quattuor sat magnis armato. Abdomen margine laterali pone medium in lobos duos triangulares ampliato. Femora antica subtus biseriatim spinosa.

\section{Vesbius Stål.}

Hem. afr. III. p. 50.

1. V. purpureus Thunb. = Cimex purpureus Thunb. Nov. 
ins. spec. III. p. 57. fig. 67. (1784); Reduvius purpureus Thunb. Hem. rostr. cap. III. p. 4 (1822); Harpactor milthinus H.-Sch. Wanz. Ins. VIII. p. 82 fig. 850. (1848).

\section{Vesulus Stål.}

Hem. afr. III. p. 51.

1. V. atripes Stål. Pallidissime rufo-testaceus, subtus dilute testaceo-stramineus; capite superne, excepta basi colli, antennis, rostro, articulo secundo apice et tertio flavo-piceis exceptis, $f e-$ moribus, tibiis tarsisque nigris; femoribus posterioribus basin versus pallide testaceo-stramineis; membrana subfusco-vinacea; alis infuscatis; thorace lobo postico pone medium disci tuberculis duobus acute conicis armato, unte tubercula obsolete bicarinato, angulis lateralibus acute produclis; articulo primo antennarum capite, thorace scutelloque ad unum paullo longiore. $\sigma^{\top}$. Long. 14, Lat. $3 \frac{1}{2}$ mill. - Insula Aru. (Mus. Holm.)

\section{Velinus Stål.}

Hem. afr. III. p. 52.

Ad hoc genus pertinent Reduvins malayus Stal é lobatus Stål nec non Euagoras nigrigenu A. et $\mathbf{S}$.

\section{Tunes Stål.}

Hem, afr. III. p. 52.

1. T. saucius Stål. Niger, nitidus, glaber; macula maxima lobi postici thoracis, scutello basin versus ventreque sanguineis; scutello pone medium rostroque stramineis; membrana alisque infu-

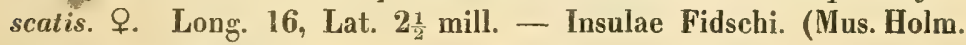
et Coll. A. Dohrn.)

\section{Amulius S tål.}

Hem. afr. III. p. 99.

Ad hoc genus pertinent Ectinoderus quadripunctatus Stål et nova species e Malacca.

\section{Tydides S tål.}

Hem. afr. III. p. 113.

Typus generis: Pirates rufus Serv.

\section{Voconia Stål.}

Hem. afr. III. p. 120.

1. V. pallidipes Stål. Nigra; rostro, spina apicali scutelli, parle coriacea hemelytrorum, abdomine pedibusque testaceo-flavescentibus; macula parva pone medium clavi et fascia latissima pone medium corii nigris; membrana fusca, vitta obliqua, posterius ab- 
breviata, indistincta, fusco-flavescente. ㅇ. Long. 10, Lat. $2 \frac{1}{2}$ mill. - Moreton Bay. (Mus. Holm.)

\section{Veseris Stål.}

Hem. afr. III. p. 121.

Typus generis: Sphaeridops rugosicollis Stal.

Vellejus S tål.

Hem. afr. III. p. 122.

Typus generis: Opsicoetus multispinus StåI.

Velitra $S t$ ål.

Hem. afr. III. p. 122.

Ad hoc genus pertinent Opinus rubro-pictus A. et S. et Cerilocus albo-plagiatus St兄.

\section{Vescia Stål.}

Hem. afr. III. p. 123.

1. V. spicula Stål. Piceo-nigra, nitidula; maculis marginalibus abdominis pedibusque posticis piceo-flavescentibus; margine interiore clavi et corii, hujus etiam angulo imo apicali maculaque membranae basali prope apicem corii flavo-testaceis. ㅇ. Long. 8, Lat. 2 mill. - Brasilia borealis. (Mus. Holm.)

Valentia Stål.

Hem. afr. III. p. 144.

Typus generis: Petalochirus apetalus Vuillf r.

Staccia Stål.

Hem. afr. III. p. 150.

1. S. diluta Stål =Oncocephalus dilutus Stål Freg. Eug. resa. Ins. p. 263, 122 (1858).

Caput subtus ante oculos utrimque spina longa armatum. Femora antica subtus utrimque spinis sat magnis remotis armata.

2. S. plebeja Stål. Pallide tesiaceo-flavescens; femoribus posticis apicem versus testaceis. ㅇ. Long. $8 \frac{1}{2}$, Lat. 2 mill. - Ceylon. (Coll. A. Dohrn.)

S. dilutae simillima, capite crassiore, subtus ante oculos spinis longis destituto, femoribus anticis subtus extus spinis magnis destitutis differt.

\section{Agylla Stål.}

Hem. afr. III. p. 150.

1. A. nigricans Stål. Nigricans; pedibus dilute sordide fla. vescentibus; femoribus dense et confluenter nigro-conspersis; trochanteribus, tibiis basi tarsisque nigro-fuscis: membrana fusca, mi- 
nute pallido-conspersa; marginibus abdominis maculis minutis pallide sordide flavescentibus ornatis $\sigma$. Long. 12, Lat. 3 mill. Adelaide. (Mus. Holm.)

Caput thorace paullo brevius, parte postoculari parte anteoculari sublongiore, retrorsum paullo angustata, subtus utrimque ante oculos spinulis parvis, pone oculos spinulis majoribus armatum. Antennae breves, articulo primo dimidio capite paullo longiore, basi graciliore. Thorax antrorsum valde angustatus, postice quam antice plus triplo latior, marginibus lateralibus acutis, subprominulis, carinis duabus antrorsum nonnihil convergentibus, anterius abbreviatis.

\section{Apronius Stål.}

Hem. afr. III. p. 150.

1. A. rapax Stål. Flavo-lividus; arliculo primo antennarum, capite thoraceque, hujus basi excepta, infuscatis; hemelytris obsolete fusco-variegatis, macula minuta corii, prope medium clavi posita, fusca; abdomine leviler infuscato, minute pallido-guttulato; femoribus fusco-conspersis; tibiis anterioribus fusco-triannulatis. ㅇ.

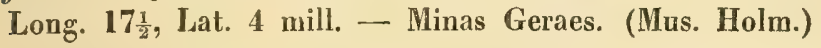

Caput thorace vix brevius, cylindricum, parte anteoculari parte postoculari nonnibil longiore, subtus inter oculos spinis quattuor per paria dispositis et posterius spinulis duabus obsoletis armatum. Antennae articulo primo parte anteoculari capitis paullo longiore. Rostrum articulis primo et secundo aeque longis, parte anteoculari capitis singulatim vix longioribus. Thorax postice quam antice fere plus triplo latior, medio levissime constrictus, angulis lateralibus acutiusculis, vix prominulis, lobo postico obsoletissime bicarinato.

\section{Nitornus S $\mathrm{S}$ tål.}

1. N. desiccatus A. et $S$. Sat dense sericeus; capite fere thoracis longitudine, cylindrico, parte anteoculari parte postoculari fere triplo longiore; ocellis haud elevatis; thorace posterius quam antice duplo latiore, pone medium leviter obtuseque constricto, carinis duabus abbreviatis minus distinctis posterius instructo, angulis lateralibus rotundatis, haud prominulis; abdomine ampliato, segmentis tertio, quarto, quinto et sexto margine laterali apicem versus paullo rotundato-prominulo; articulo primo antennarum parte anteoculari capitis fere dimidio breviore.

Oncocephalus desiccatus A. et S. Hist. des Hém. p. 287. 1. (1843) sec. ex. typ. 


\section{Barce Stål.}

Hem. afr. III. p. 163.

1. B. annulipes Stål. Griseo-straminea; femoribus tibiisque dilute fusco-multiannulatis; vitta utrimque laterali inferiore capitis, pectore abdomineque fuscis, hoc pallido-consperso, maculis parvis discoidalibus utrimque in seriem positis maculisque marginalibus griseo-stramineis. ㅇ. Long. 10, Lat. $\frac{3}{4}$ mill. - Wisconsin. (Mus. Holm.)

Antennae articulo primo prothorace, mesothorace et metathorace ad unum sublongiore, articulis reliquis mutilatis in exemplo descripto. Caput anguste ovale, partibus anteoculari et postoculari aeque longis. Prothorax capite vix duplo longior, pone medium constrictus, parte ante stricturam posita parte posteriore duplo longiore, illius lateribus parallelis, hac retrorsum sensim ampliata. Hemelytra parce fusco-conspersa.

\section{Carambis Stål.}

Hem, afr. III. p. 163.

Typus generis: Emesa caspica Dohrn.

\section{Rargylia Stål.}

Hem. afr. III. p. 163.

Typus generis: Emesa juncea Er.

\section{Amorgius $\mathrm{S}$ tål.}

Hem. afr. III. p. 179.

Typus generis: Belostoma colossicum Stål.

Poecilopsaltria Stål.

Hem. afr. IV. p. 2.

1.P. octoguttat a Fabr. Testaceo-flavescens, albido-sericea; disco thoracis testaceo; fasciis duabus capitis maculisque scutelli nigris; fascia anteriore capilis in fronte flavo-maculata; tegminibus vitreis, parte vix dimidia basali fusca, macula prope apicem areae radialis fasciaque anteriore albidis, opacis, anastomosibus fusco-marginatis, maculis interdum deficientibus parvis, in series duas subapicales positis, fuscis; alis nigro-fuscis, venis basin versus sanguineis, limbo lato enervi decolore, vitreo; capite latissimo. రㅇ․ Long. 27, Exp. tegm. 80 mill. - Bengalia. (Mus. Holm.)

Tettigonia 8-guttata Fabr. Ent. syst. Suppl. p. 515. 22-23 (1798); Syst. Rhyng. p. 39. 33. (1803).

Tettigonia octoguttata Coq. Ill. ins. I. p. 34. Tab. 9. Fig. I. (1790).

Oxypleura sanguiflua $\mathbf{W a l k}$. 
2. P. capitata 01. Testaceo-flavescens; vilta parteque basali frontis, basi genarum, margine apicali fasciague verticis, limbo laterali postico thoracis, maculis scutelli, dorso abdominis, excepto limbo apicali segmentorum, nigris; macula prope busin frontis favescente; tegminibus vitreis, basin versus griseo-opacis, basi, fasciis duabus ante medium, anustomosibus maculisque parvis prope apicem in series duas positis nec non alis obscure fuscis vel nigrofuscis, harum macula maxima discoidali limboque apicali, parle lata media excepta, albidis; capite latissimo. \&. Lung. 28, Exp. tegm. 78 mill. - Ceylon. sec. Stoll. (Coll. Stål.)

Cicade capitata 01. Enc. méth. V. p. 754. 34. (1790.)

Oxypleura subrufa Walk.

Stoll. Cig. Fig. 103.

Platypleura Hilpa Walk. et fulvigera Walk. ad hoc genus pertinent.

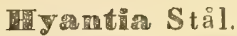

Hem. afr. IV. p. 2.

Typus generis: Cyclochila honesta Walk.

\section{Araptopsalț Soำ Stål.}

Hem. afr. IV. p. 3.

1. G. colorata Stål. Nigra; marginibus exterioribus clypei et lororum, carinis transversis macularue subbasali frontis, maculis duabus ante medium verticis, linea abbreviata longitudinali anteriore thoracis, segmentis ventralibus postice pedibusque testaceo-flavescentibus; femoribus fusco-vittatis; maculis duabus magnis margineque angusto laterali thoracis, maculis duabus parvis ante medium lituraque postica scutelli ferrugineis; tegminibus alisque fusco-ochraceis, illis apicem versus fuscis, areis apicalibus macula pallida apice notatis; areis apicalibus alarum macula oblongo-triangulari fusca notatis; limbo enervi tegminum alarumque nec non harum areu anali fuscis. ㅇ. Long. 35, Exp. legm. 117 mill. - Japonia? (Coll. Stål.)

․ Segmento ventrali ultimo apice medio nonnihil emarginato; segmento dorsali ultimo abdominis nigro, lateribus flavo-testaceis.

Caput thoracis apice paullo angustius; vertice oculis paullo plus quam duplo latiore. Ocelli ab oculis quam inter se duplo longius remoti. Thorax marginibus lateralibus ab apice ultra medium reetis, vix sinuatis.

\section{Scieroptera Stål. \\ Hem. afr. IV. p. 4.}

Ad hoc genus pertinent Cicada splendidula Fabr., crocea Gu ér. et Huechys fumigata Stå. 


\section{Gaeana $\mathbf{A}$. et $\mathbf{S}$.}

1. G. festiva Fabr. Nigra; lateribus verticis teslaceis; margine angustissimo antico et basali latiore thoracis, vittis angustis quattuor sculelli tegminibusque viridi-croceis, horum areola basali, area radiali, fascia ante medium posita, maculis nonnullis pone medium, limbo latissimo apicali clavoque nigris; alis albidis, parte apicali nigra, macula albida notata. ㅇ. Long. 30, Exp. tegm. 75 mill. - India orientalis. (Nus. Holm.)

Tettigonia festiva F abr. Syst. Rhyng. p. 4I. 41. (1803).

Cicada thalassina Guér et Perch. Gen. des Ins. Hém. PJ. 2. (1834); Guér. Voy. Coq. Ins. p. 183. (1838.)

Gaeana consobrina White Proc. Zool. Soc. 1850.

Cicada Percheronii Guér. Ic. règne an. Ins. p. 355. (1838.)

\section{Graptotettix Stål.}

Hem. afr. IV. p. 4.

1. G. guttatus Stål. Nigricans; fronte, maculis quatluor ovalibus thoracis, maculis duabus magnis scutelli abdominegue sordide favescentibus; tegminibus alisque fuscis. 오. Long. 25, Exp. tegm. 67 mill. - Himalaya. (Coll. St ål.)

․ Segmento ventrali ultimo apice profunde lateque sinuato.

Caput apice thoracis paullo angustius; fronte valde prominula. Thorax marginibus lateralibus leviter sinuatis:

\section{Eeptopsaltria $S$ tål.}

Hem. afr. IV. p. 4.

Ad hoc genus pertinent Cicada tuberosa Sign., quadriluberculata Sign., guttularis Walk. etc.

\section{Dundubia A. et S., Stål.}

1. D. mannifera Lin. Pallide subolivaceo-virescens vel Aavescens; fronte valde tumida; abdomine dorso maculis lateralibus fuscis nolato. $\delta$. Long. 43, Exp. tegm. 110 mill.

б. Operculis elongatis, prope basin coarctatis, pone medium latissimis, apice rotundatis.

Cicada mannifera Lin. Mus. Ad. Frid. p. 84. (1754) excl. syn. Tettigonia vaginata F abr. Ent. syst. IV. p. 18. 7. (1794); Syst. Rhyng. p. 35. 10. (1803).

Cicada virescens Ol. Enc. méth. V. p. 747. 5. (1790.)

Stoll. Cig. fig. 3.

\section{Cosmopsaltria Stål.}

Hem. afr. IV. p. 5.

Ad hoc genus pertinent Cicada doryca B oisd.. didyma Boisd., 
chlorogaster B oisd., spinosa Fabr., obtecta Fabr., Aavida Guér. (= Dundubia saturata Walk.), Dundubia lineifera Walk., poecilochlora Walk. et bicaudala Walk., nec non plures aliae.

Pomponia S tål.

Hem. afr. IV. p. 6.

Ad hoc genus pertinent Cicada fusca Oliv. et imperatoria Westw., Dundubia Urania Walk., linearis Walk. et Thalia Walk. nec non Carineta expansa Walk.

Henicopsaltria $S$ tål.

Hem. afr. IV. p. 7.

Ad hoc genus pertinent Cicada Eydouxii Guér., Fidicina Fullo Walk. et nubivena Walk., verisimiliter etiam Cicada perulata Guér. et Thopha interclusa Walk.

\section{Selymbria Stål.}

Cephaloxys nutans Walk. ad hoc genus est referenda.

Vosola Stål.

Hem. afr. IV. p. 7.

1. N. paradoxa Stål. Fusco-testacea, griseo-sericea; abdomine pedibusque sordide flavo-testaceis; tegminibus alisque sordide hyalinis, griseo-venosis, illis rugosis, prope apicem serie macularum parvarum fuscarum obsolelarum nolatis, venis longitudinalibus prope apicem leviter fusco-marginatis; maculis minutissimis numerosis scutelli denudatis. $\sigma^{7}$. Jong. 29, Exp. tegm. 76 mill. - Bolivia. (Mus. Holm:)

б. Operculis transversis, apice rotundatis, nonnihil distantibus.

Caput thorace paullo angustius, vertice oculis fere triplo latiore. Ocelli ab oculis quam inter se vix duplo longius remoti. Thorax lateribus parallelis, vix sinuatis, postice haud ampliatus. Tegmina apicem versus sensim angustata, prope basin latissima, vena ulnari interiore, aream ulnarem interiorem terminante, leviter curvata, hac area pone medium retrorsum nonnihil ampliata, areis apicalibus septima et octava fere aeque longis, areis apicalibus prima et tertia longissimis, aeque longis.

\section{Fidicima A. et $\mathbf{S}$.}

Ad hoc genus referendae sunt Cicada viridis Ol. (Stoll. Cig. Fig. 127.) et C. bicolor 01.

Cieada Lin., Stål.

Ad hoc genus pertinent Cicada angularis Germ. (e Nova Hollandia), Cicada bimaculata 01. (= atrovirens Guér.) et Dundubia fuscipes Stål. 


\section{Tympanoterpes Stål.}

Ad hoc genus etiam pertinet Cicada murginala O1. (= Tel. tigonia viridis $\mathrm{Eabr}$.)

\section{Wmathia Stål.}

Hem. afr. IV. p. 8.

1. E. aegrota Stål. Pallidissime olivacea, parce griseo-sericea; vilta media antrorsum ampliata limboque postico thoracis, maculis qualtuor triangularibus basin scutelli attingentibus, mediis parvis, lateralibus magnis, nec non dorso abdominis subtestaceis; tegminibus alisque vitreis, venis pallide olivaceo-virescentibus, apicem versus fuscis, macula anaslomosium duarum exteriorum maculaque subapicali ad marginem exteriorem tegminum fuscis; anastomosi prima alarum fusco-marginata, limbo enervi intus ad aream analem nec non area anali basi fuscis; vittis femorum apiceque tibiarum fuscescentibus. $0^{\top}$. Long. 20, Exp. tegm. 50 mill. - Bombay. (Mus. Holm.)

ऽ. Operculis parvis, obliquis, oblongis; segmento ventrali primo inter opercula triangulariter elevato.

Caput apice thoracis rix latius; vertice oculis vix plus quam duplo latiore; fronte prominula. Ocelli ab oculis quam inter se nonnihil longius remoti. Thorax lateribus parallelis vel antrorsum subampliatus, basi subito ampliatus. Femora antica trispinosa.

\section{Bacturia Stål.}

Hem. afr. IV. p. 9.

Ad hoc genus pertinent Cicada conviva Stål el nonnullae species novae.

\section{Saticula Stål.}

\section{Cicada. 5. Gruppe. Hagen. Ent. Zeit. XVII. p. 138.}

1. 4. coriaria Stål. Supra nigra, nitens; prothoracis lateribus, segmentis abdominis intermediis aurantiaco-marginalis; subtus flava, pedibus flavidis, femoribus supra, exlus et intus fascia nigra latiori in anticis, tibiis tarsisque apice (anticis totis) nigris; alis fuscis, venis nigris, costa late aurantiaca, basi anticorum fuscoferruginea. $\sigma^{7}$. Long. 13, Exp. tegm. 27 mill. (sec. Hagen.)

Cicada violacea Hagen Ent. Zeit. XVIII. p. 139. 18. (excl. syn.)

Platypleura $A$, et $\mathbf{S}$.

1. P. cervina Walk. =P. straminea Walk.

\section{Aethalion Latr.}

1. A. apicale Walk. = A. semiannulatum Sign.

2. A. gratum Walk. = A. dilatatum Stål. 


4.

s.

\section{,} tosin.

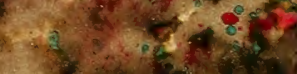

|||

(1)

(1) $\begin{array}{llll}3 & 9088 & 00792 & 1034\end{array}$

are

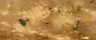

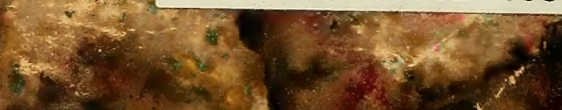

39

Ysi:

$-2+3 x$

$2+5$

ristox

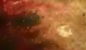

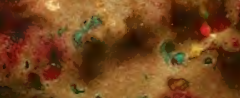

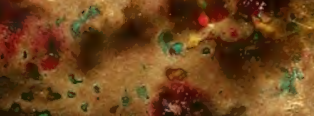

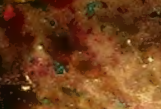

the

$6+5+4 x^{2}+2$

(5)

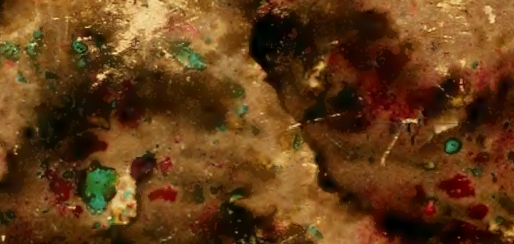

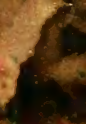

(5)

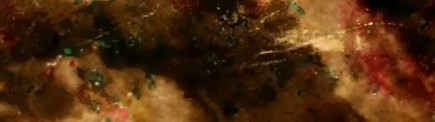

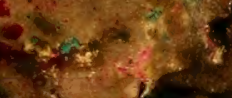

$\lim ^{2} 2$

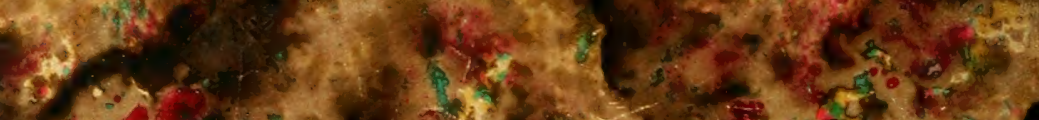

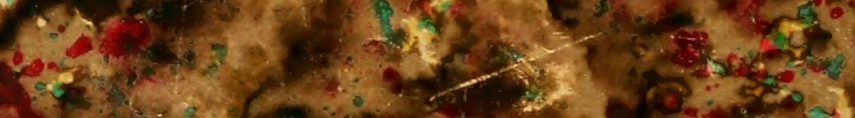

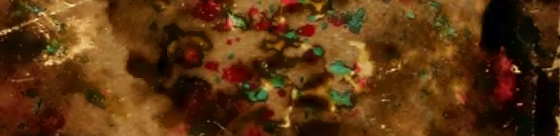

2

Ais

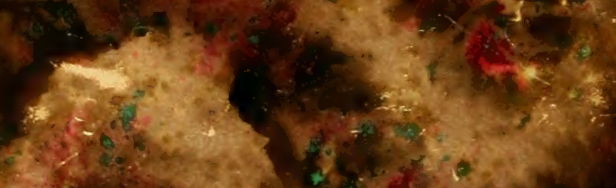

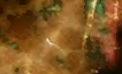

B.

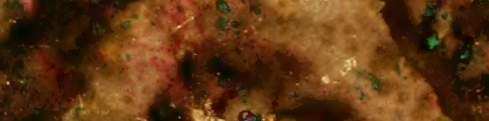

